\title{
Effects of spatial aggregation on competition, complementarity and resource use
}

\author{
KAREL MOKANY, ${ }^{1 \star}$ JULIAN ASH ${ }^{1}$ AND STEPHEN ROXBURGH ${ }^{2}$ \\ ${ }^{1}$ School of Botany and Zoology, The Australian National University, Canberra, ACT 0200, Australia \\ (Email: karel.mokany@anu.edu.au) and ${ }^{2}$ Bushfire Co-operative Research Centre, School of Biological, \\ Earth and Environmental Sciences, The University of New South Wales and ENSIS, Kingston, ACT, \\ Australia
}

\begin{abstract}
The spatial distributions of most species are aggregated to varying degrees. A limited number of studies have examined the effects of spatial aggregation on interspecific and intraspecific interactions, generally finding that spatial aggregation can enhance coexistence between species by reducing the capacity for interspecific competition. Less well studied are the effects of spatial aggregation on complementarity (i.e. differences in resource use strategies) and resource use. Our primary hypothesis was that spatial aggregation reduces the complementarity between species owing to: (i) less interspecific interactions as a result of spatial separation; and (ii) less differences between species as a result of phenotypic plasticity. We further postulate that these negative effects of spatial aggregation on complementarity will reduce resource use by the community. Here we test these hypotheses in a pot experiment in which we applied three levels of spatial aggregation to three sets of two-species mixtures of herbaceous perennial plant species from native grasslands of south-eastern Australia. Both root and shoot biomass were significantly affected by spatial aggregation, although the nature of these affects depended upon the species involved, and the relative strengths of interspecific versus intraspecific competition. Complementarity between species in the distribution of their green leaves decreased significantly as spatial aggregation increased for one of the species mixtures, providing some evidence in support of our hypothesis that aggregation reduces complementarity through phenotypic plasticity. Spatial aggregation also altered light interception and use of soil moisture resources, although these effects were dependent on the species involved. We suggest that clear effects of spatial aggregation on complementarity and resource use may be obscured by the idiosyncratic way in which neighbour identity influences plant growth and hence plant size, limiting the ability to generalize, at the community level, any underlying effects of spatial pattern on ecological process.
\end{abstract}

Key words: Austrodanthonia caespitosa, Hypochaeris radicata, Themeda australis.

\section{INTRODUCTION}

The way in which individuals of a species are spatially distributed has long been a focus of ecological research (Harper 1961; Turner 1989). Rather than being randomly or uniformly distributed, the distributions of most species are aggregated at one or more spatial scales (Herben et al. 2000). Aggregated spatial distributions have been observed for many animal species (e.g. Perry 1995; Veech et al. 2003; Bourque \& Desrochers 2006), although spatial aggregation has more often been studied and observed in plant species, owing to their sessile nature (e.g. Rees et al. 1996; Law et al. 1997; Watkinson et al. 2000).

Intraspecific spatial aggregation may be generated by a number of mechanisms. Most obviously, the distribution of a species may be aggregated in places where the

${ }^{\star}$ Corresponding author.

Accepted for publication July 2007. resources and environmental conditions are most beneficial for growth and reproduction. However, endogenous factors may also be important in generating intraspecific aggregation, including limited dispersal of propagules/offspring, clonal growth and sociality (Rees et al. 1996; Stoll \& Prati 2001). Disentangling these endogenous and exogenous drivers of spatial aggregation in natural communities remains elusive.

Although the aggregated distributions of many species have been well documented, there has been less attention given to the possible effects of spatial aggregation on ecological processes. One of the most significant potential effects of spatial aggregation on communities is thought to be the promotion of coexistence between species. Where two competing species in a community are aggregated in different spatial areas, the amount of interspecific interactions is reduced, while intraspecific interactions increase (Murrell et al. 2001; Lenssen et al. 2005). Spatial aggregation may therefore limit the negative effects of 
a competitively superior species on inferior species, allowing the inferior species to survive and persist in the community. This effect has indeed been observed in a number of empirical studies (Schmidt 1981; Bergelson 1990; Rees et al. 1996; Stoll \& Prati 2001; Monzeglio \& Stoll 2005). Hence, spatial aggregation of species distributions can facilitate the coexistence of species, and may therefore result in the maintenance of higher levels of biodiversity (Bergelson 1990; Monzeglio \& Stoll 2005).

Empirical studies have indicated that spatial aggregation can influence the outcome of competition between species (Rejmanek 2002); however, many important questions remain unanswered. Key among these are whether spatial aggregation influences resource use strategies, the degree of complementarity between species (i.e. differences in resource use strategies (Petchey 2003)), and subsequent resource use by the community (Schmid et al. 2002; Simioni et al. 2003; Maestre et al. 2005).

Recent research has found that biodiversity can have significant effects on ecosystem processes (Hooper et al. 2005). One of the main mechanisms proposed to explain these effects is that biodiversity increases the degree of complementary resource use between species (Naeem et al. 1994; Hector 1998). Although the attention given to the effects of biodiversity on ecosystem processes is warranted, the potential for other attributes of a community to influence the complementarity between species has received less interest, despite the likelihood of significant effects on ecosystem processes (e.g. Dimitrakopoulos \& Schmid 2004). The spatial distribution of species in a community may be one of the more important factors that influence the complementarity between species, and therefore ecosystem processes.

The major hypothesis we set out to test was that increasing intraspecific spatial aggregation reduces the level of interspecific interactions, leading to a reduction in complementarity between species and hence reduced total resource use. We postulate that as spatial aggregation increases, complementarity may be reduced in two ways. First, the potential for any differences between species in resource uptake strategies to be expressed through resource use may be reduced by having less interaction space between species as spatial aggregation increases. As interspecific interactions are only possible at the edges of monospecific patches, and the patch edge relative to patch area decreases as patch size increases, we would expect a decrease in the capacity for complementary resource use with increasing patch area (De Boeck et al. 2006). Second, reduced pressure to partition resources between species may result in more similar morphologies and resource uptake strategies (less differences between species) owing to phenotypic plasticity (Stoll \& Weiner 2000). This would be equivalent to species altering their realized niche, dependent on the level of interspecific interaction (Giller 1984).

We examined this hypothesis in a pot experiment where three levels of spatial aggregation were applied to two-species mixtures from a pool of three perennial herbaceous plant species common in native grasslands of south-eastern Australia. The specific objectives of this study were to examine whether: (i) above- and below-ground attributes of species were influenced by spatial aggregation; (ii) use of light and soil moisture were influenced by spatial aggregation; (iii) complementarity in resource acquisition was influenced by spatial aggregation; (iv) plant attributes and ecosystem processes varied between the edges and centre of patches; and (v) the trends observed varied when different species were competing.

\section{MATERIALS AND METHODS}

\section{Experimental design}

We investigated the effects of intraspecific aggregation in an experiment conducted outdoors (Plant Culture Facility, at The Australian National University, Canberra, Australia) in large 'pots', with three perennial species common and abundant in native grasslands of south-eastern Australia. Species were chosen to represent different growth forms: large tussock, small tussock and basal rosette. Austrodanthonia caespitosa (Gaud.) H.P. Linder is a native $\mathrm{C} 3$ grass which forms small tussocks (leaves up to $20 \mathrm{~cm}$ high), Themeda australis (R.Br.) Stapf is a native C4 grass forming larger tussocks (leaves up to $35 \mathrm{~cm}$ high), while Hypochaeris radicata $\mathrm{L}$. is an exotic broadleaf species forming flat basal rosettes (leaves up to $10 \mathrm{~cm}$ high). Both Austrodanthonia caespitosa and Themeda australis have fibrous root systems while Hypochaeris radicata generally has a small number of thick tap-roots. Hereafter we use the genus name for each species.

Two factors were manipulated in this study: the degree of spatial aggregation and the identities of competing plant species. Three spatial aggregation treatments were applied in a checkerboard design to mixtures of two species from the pool of three species, with all species combinations applied (i.e. $A v H, H v T$, $A v T)$ (Fig. 1). The aggregation treatments were: low (one plant per patch), intermediate (four plants per patch) and high (24 plants per patch) (Fig. 1). Monocultures (48 plants per patch) of each species were also applied, and may be considered as the greatest level of spatial aggregation possible. Each spatial aggregation treatment for each species combination treatment was replicated five times, as were the monocultures. The soil surface of each pot $(40 \times 30 \mathrm{~cm})$ was divided equally into 48 squares $(5 \times 5 \mathrm{~cm})$, with a single plant 

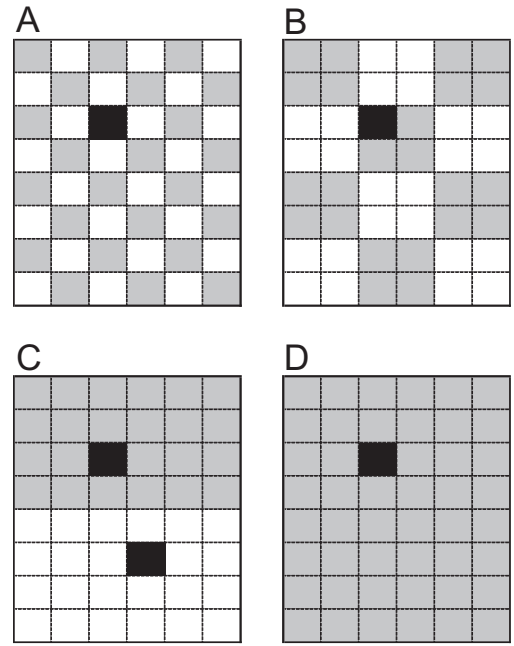

Fig. 1. The experimental design, with spatial treatments: (A) low aggregation, (B) intermediate aggregation, (C) high aggregation and (D) monoculture. Each treatment is $30 \times 40 \mathrm{~cm}$, and the positions of plants of each of two species are indicated by either grey or white squares $(5 \mathrm{~cm} \times 5 \mathrm{~cm})$. Black squares indicate the $6 \mathrm{~cm}$ diameter PVC pipe used for measuring soil moisture.

being planted in the centre of each $5 \mathrm{~cm}$ square based on the spatial aggregation treatments (Fig. 1). This density of plants is typical in the grassland from which the species were collected (K. Mokany, pers. obs. 2005). Hypochaeris was propagated from seed and seedlings planted, while live plants for the two native grass species were collected from a single grassland site, their roots washed free of soil and ramets of similar size planted.

Pots consisted of plant bags $(200 \mu \mathrm{m}$ UV resistant plastic) abutted against each other in two rows of 30 pots each, within a solid superstructure of fibro-cement sheets. Pots were $40 \times 30 \mathrm{~cm}$ wide, filled to $70 \mathrm{~cm}$ depth with a sandy loam soil mixture (60\% sand, $40 \%$ sieved loam), with drainage holes at the base of each pot. Pots of this size are likely to generate soil moisture regimes typical of field soils. To measure soil moisture throughout the soil profile, vertical PVC tubes $(60 \mathrm{~mm}$ diameter) were inserted to the base of each pot at set locations within each pot (Fig. 1). The location of the 12 treatments (species combination $\times$ spatial aggregation) was randomized within each of five blocks, with two and a half blocks per row in the experimental set up.

All species were planted out in the appropriate experimental treatments in August 2005, with the experiment terminated and plants harvested in February 2006 . Over this time, pots were watered at a moderate level to supplement natural rainfall (twice weekly during warmer months), and the few weeds that emerged were removed. All reported measurements were taken in late January and February 2006.

\section{Quantifying ecosystem processes}

The intensity of photosynthetically active radiation (PAR) intercepted by the plant canopy was determined by measuring PAR above the canopy and below the canopy ( $15 \mathrm{~mm}$ above the soil surface) with a LI-COR Quantum (LI-185A) with PAR meter. PAR was measured at both the edge of patches (for low-, intermediate- and high-aggregation treatments) and within patches (for intermediate- and highaggregation, and monoculture treatments) for each spatial aggregation/species combination treatment, with two replicate measurements taken per position (patch edge and within each patch) per pot, giving 10 replicates per position per treatment. PAR measurements were made between $11 \mathrm{AM}$ and $1 \mathrm{PM}$ on a cloudless day.

To quantify effects of the spatial aggregation and species combination treatments on soil moisture use, the soil in each pot was fully saturated and then left unwatered for a 12-day drying period. Over this time the mean maximum daily temperature was $31.9^{\circ} \mathrm{C}$, and mean daily pan evaporation was $8.3 \mathrm{~mm}$. Pots were covered for short periods to exclude the small amount of rain that fell during this drying period. Volumetric soil moisture content was estimated at $10 \mathrm{~cm}$ depth intervals throughout the soil profile (depth $70 \mathrm{~cm}$ ) using a frequency domain reflectometry probe (Sentek Diviner 2000) in the preestablished access tubes. This indicates the soil moisture content within a radius of approximately $10 \mathrm{~cm}$. The position of the access tubes with regard to the species of plant it replaced (Fig. 1) in the low and intermediate aggregation treatments was alternated randomly within treatments between the five blocks. Measurements were taken at the commencement of drying, and then $2,3,4,6,8,10$ and 12 days after the commencement. In quantifying changes in soil moisture over the drying period, data were first standardized by the soil moisture at the commencement of the drying period (saturated), then the average soil moisture content over the drying period calculated.

\section{Quantifying plant biomass}

Following the drying period in which soil moisture dynamics were measured, the above- and belowground biomass of each species in each spatial aggregation/species combination treatment was quantified.The total above-ground biomass was determined for four plants per species per pot in the low and intermediate aggregation and monoculture treatments. For one plant randomly selected from within these four, biomass was harvested at each height interval above the soil surface $(0-5,5-10,10-20,20-40,40-60,60-80$, $80-100 \mathrm{~cm}$ ) and separated into green leaf and 
non-green biomass. For each species in the highaggregation treatments, four plants were harvested from the row of plants at the edge of the patch (first row - where it abuts the other species), three plants from the second row and four plants from the third row. From each row, one plant was randomly selected and its biomass harvested at each height interval and separated into green leaf and non-green leaf. No plants growing at the edge of the pots were harvested owing to potential edge effects.

The root biomass was determined for two plants per species per pot in the low and intermediate aggregation and monoculture treatments. For each species in the high-aggregation treatments, the root biomass of two plants were harvested from the row of plants at the edge of the patch (where it abuts the other species), two plants from the row of plants next to the edge and two plants from the next row of plants. All root systems harvested were randomly selected from plants that had their above-ground biomass harvested. For all plants where roots were harvested, the side of the pot was exposed, the soil mixture washed clear from the roots with water and the roots of the target plants separated from all other plants. The root system of each plant was then washed clean and its biomass separated into $10 \mathrm{~cm}$ depth intervals. All biomass harvested was dried at $80^{\circ} \mathrm{C}$ for 3 days prior to weighing.

In order to quantify the complementarity in resource acquisition attributes between species, a 'complementarity index' was calculated as the difference in the vertical distributions of both green leaf and root biomass between species. For both green leaf biomass and root biomass, the proportion of biomass at each height (for leaves) or depth (for roots) interval for each plant was determined. The difference between the two species in a mixture with regard to the proportional distribution of green leaf and root biomass with height or depth was then calculated, using the complement of the niche overlap measure of Schoener (1970). Specifically, the complementarity index (CI) was calculated as: $\mathrm{CI}={ }_{1}^{1 / 2} \Sigma\left|p_{x, i}-p_{y, i}\right|$, where $p_{x, i}$ and $p_{y, i}$ are the proportions of species $x$ and $y$, respectively, in height or depth category $i$, with the summation over all height or depth categories. The greater the complementarity index, the more complementary two species are with regard to the distribution of their green leaf or root biomass.

\section{Statistical analyses}

Because of the unbalanced structure of crossed treatments in this study (i.e. some combinations of aggregation treatment and species combination treatment are impossible - e.g. a monoculture with two species present), we applied residual maximum likelihood linear mixed models for the majority of our statistical analyses (Genstat 7th Ed.). For the biomass and plant attribute data, each of the three species was analysed separately for each variate. The initial fixed model was the main and interactive effects of aggregation treatment and the competing species, while the random model included positional information of both the pot and the block. Where significant effects were detected, the fixed model was simplified to include only significant factors, and significantly different treatments identified through the examination of the least significant difference. Model residuals were examined and where necessary, data were transformed (log, square root and cubic) to correct for skewed distribution of residuals and non-constant error variance.

This analytical approach was applied consistently, with the primary factors in the fixed model altered to include the position of measurement where appropriate. For ecosystem variables and soil moisture data, each of the three species combinations were analysed separately. All figures show actual mean values with bars indicating standard errors, however, the statistical results presented refer to modelled means analysed by residual maximum likelihood.

\section{RESULTS}

\section{Biomass measures}

Effects of the spatial aggregation treatments on plant biomass varied between species and species combinations. Austrodanthonia plant biomass (root + shoot) generally increased from low to high spatial aggregation (Fig. 2A), although this tendency was not significant (Wald $\left.(W)_{3,2}=2.34, P=0.071\right)$. The plant biomass for Austrodanthonia was significantly greater when in monoculture than the mixture with Hypochaeris ( $\left.W_{2}=4.20, P=0.015\right)$. Hypochaeris plant biomass tended to peak at intermediate level of aggregation in both species mixtures (Fig. 2B). Plant biomass for Hypochaeris was significantly lower in monoculture than at intermediate or high-aggregation $\left(W_{3}=2.99\right.$, $P=0.030)$ and both species mixture treatments $\left(W_{2}=5.93, P=0.003\right)$. There were non-significant tendencies for Themeda plant biomass to increase from low to high aggregation when grown with Austrodanthonia but decrease from low to high aggregation when grown with Hypochaeris (Fig. 2C), and there was significantly greater plant biomass for Themeda when grown in monoculture compared with the other spatial aggregation $\left(W_{3}=3.09, P=0.026\right)$ or species combination $\left(W_{2}=8.70, P<0.001\right)$ treatments. The trends shown in the data for plant biomass were similar for each of the three species when plant biomass was separated into the root and shoot biomass components (data not shown). 

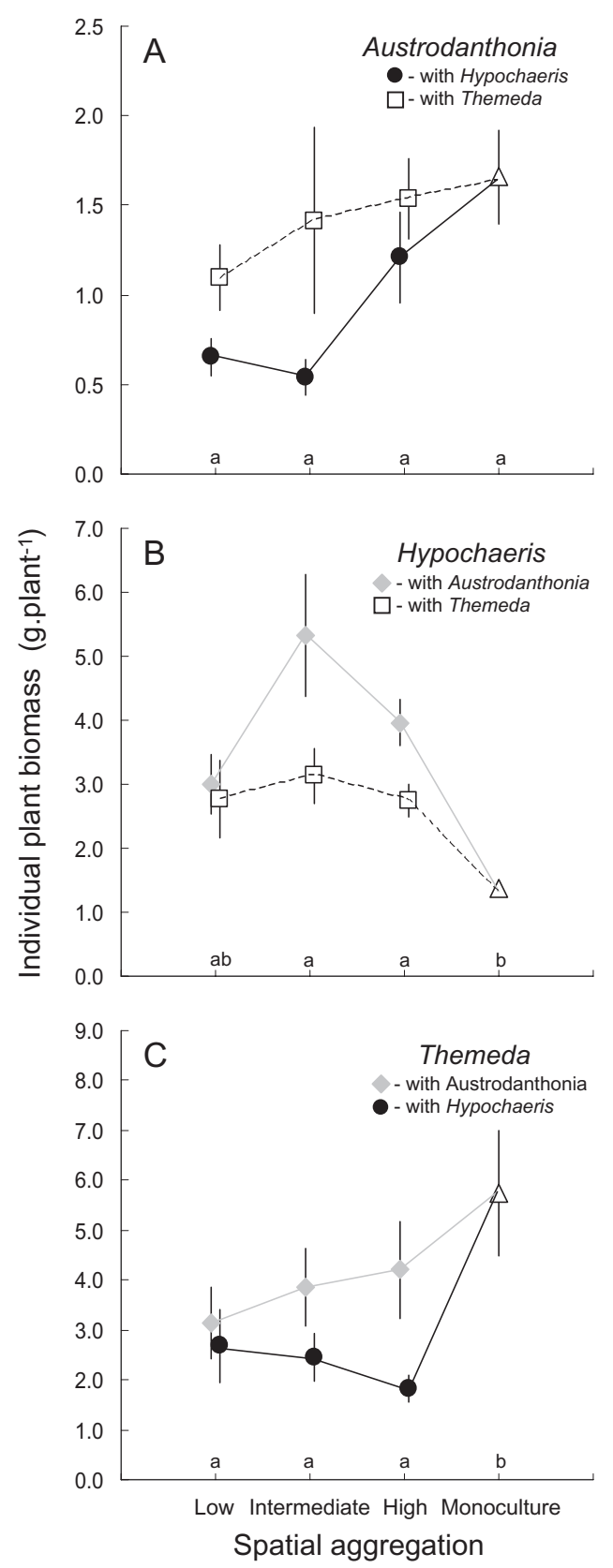

Fig. 2. Individual plant biomass in each spatial aggregation treatment for (A) Austrodanthonia, (B) Hypochaeris and (C) Themeda, when grown in combination with either Austrodanthonia $(\diamond)$, Hypochaeris $(\bullet)$, Themeda $(\square)$, or in monoculture $(\triangle)$. Different letters indicate significant $(P<$ $0.05)$ differences between aggregation treatments.

Examination of biomass within each patch in the high-aggregation treatment revealed the shoot biomass for Austrodanthonia when grown with Themeda decreased from the edge of the patch to the centre $\left(W_{5}=4.38, P<0.001\right)$ (Fig. 3A). Shoot biomass of Austrodanthonia at the edge of the high-aggregation patch was significantly greater when neighbouring a
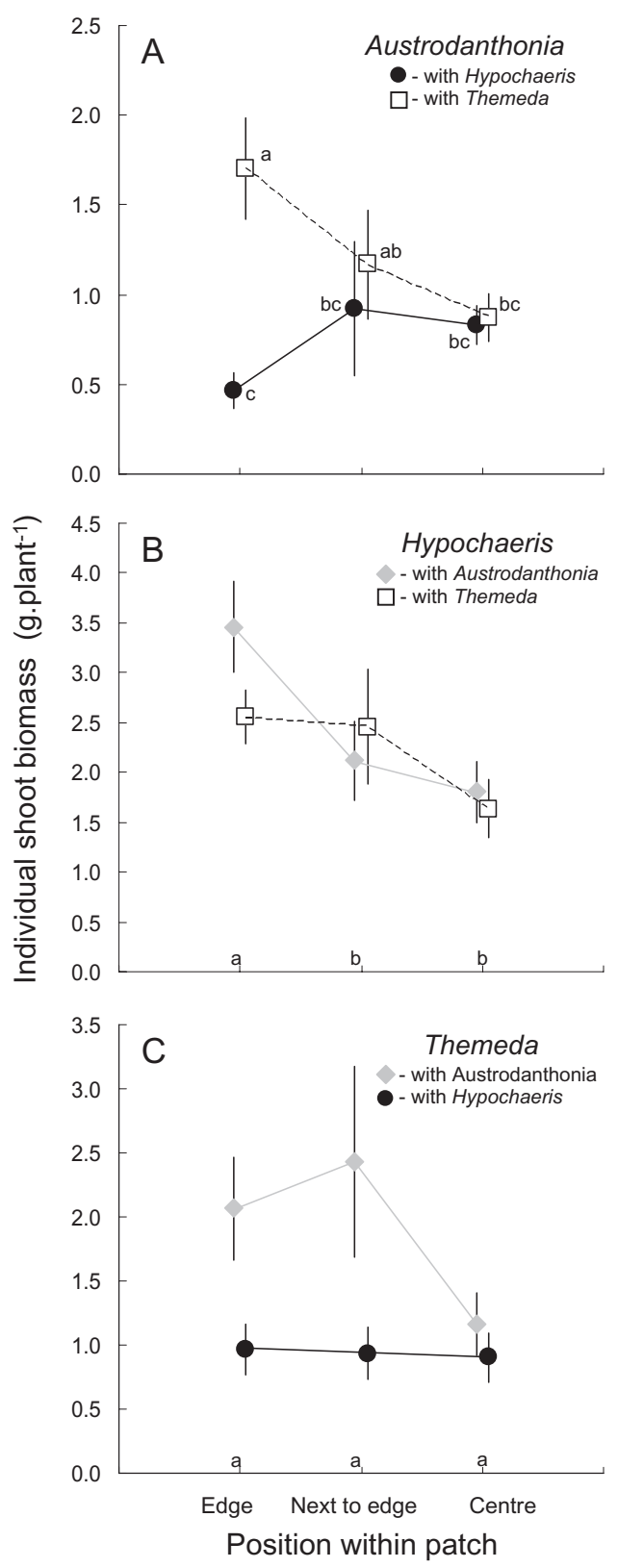

Fig. 3. Shoot biomass for plants in the high-aggregation treatment at three positions within the patch for (A) Austrodanthonia, (B) Hypochaeris and (C) Themeda, when grown in combination with either Austrodanthonia $(\diamond)$, Hypochaeris (O) or Themeda ( $\square$ ). Different letters indicate significant $(P<0.05)$ differences between patch positions.

patch of Themeda than when neighbouring a patch of Hypochaeris $\left(W_{5}=4.38, P<0.001\right)$ (Fig. 3A). Regardless of the species in the adjacent patch, shoot biomass for Hypochaeris in the high-aggregation treatment decreased significantly from the edge to the centre of the patch $\left(W_{2}=8.33, P<0.001\right)$ (Fig. 3B). Similar significant trends for Hypochaeris were also observed for both root biomass $\left(W_{2}=3.98, P=0.019\right)$ and total 


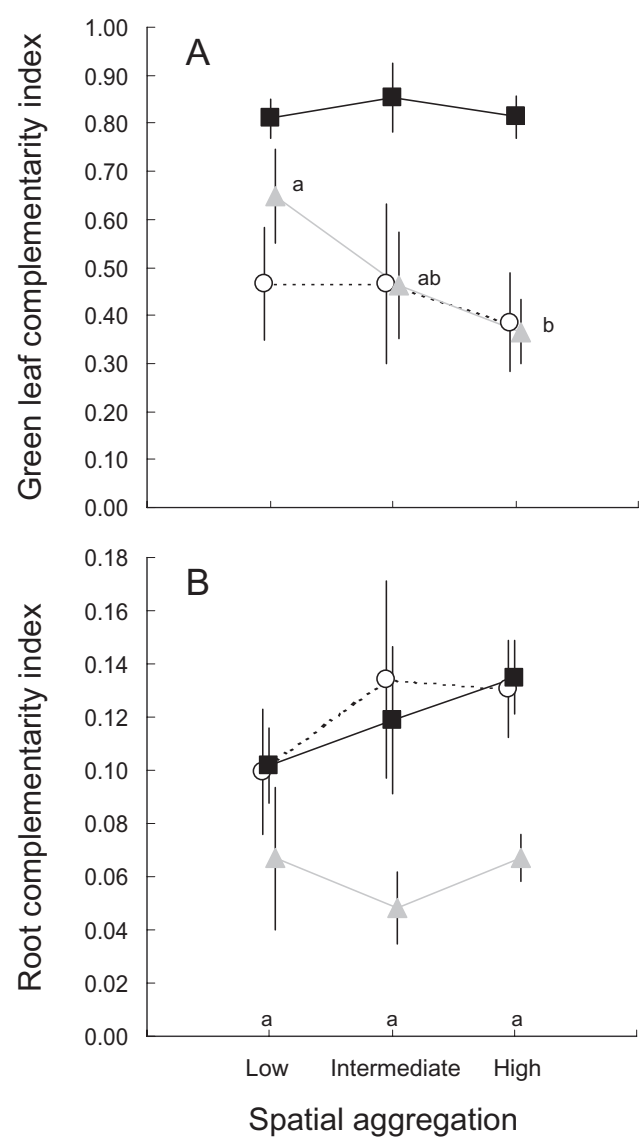

Fig. 4. Complementarity index for (A) green leaf biomass and (B) root biomass, for mixtures of Austrodanthonia and Hypochaeris (○), Hypochaeris and Themeda (ם), and Austrodanthonia and Themeda ( $\triangle$ ), for each spatial aggregation treatment. Different letters indicate significant $(P<0.05)$ differences between aggregation treatments.

plant biomass $\left(W_{2}=4.08, P=0.017\right)$. There was a non-significant trend for shoot biomass of Themeda to be lower in the centre than the edge of the highaggregation patch when grown with Austrodanthonia $\left(W_{2,2}=1.82, P=0.161\right)$ (Fig. 3C). There was significantly less green leaf biomass $\left(W_{2}=3.33, P=0.036\right)$, and significantly larger root : shoot ratios $\left(W_{2}=3.02\right.$, $P=0.049)$ for Themeda plants in the centre of the high-aggregation patch compared with the edge.

The complementarity index for green leaf distribution decreased significantly as the level of spatial aggregation increased for the mixture of Austrodanthonia and Themeda $\left(W_{2}=3.10, P=0.045\right)$ (Fig. $\left.4 \mathrm{~A}\right)$. There were no significant effects of spatial aggregation on the complementarity index for green leaf distribution for the mixtures of either Austrodanthonia and Hypochaeris $\left(W_{2}=0.12, P=0.885\right)$, or Hypochaeris and Themeda $\left(W_{2}=0.42, P=0.659\right)$ (Fig. $\left.4 \mathrm{~A}\right)$. There were no significant effects of spatial aggregation on the complementarity index for root distribution for the mixtures of Austrodanthonia and Hypochaeris $\left(W_{2}=0.48, P=\right.$
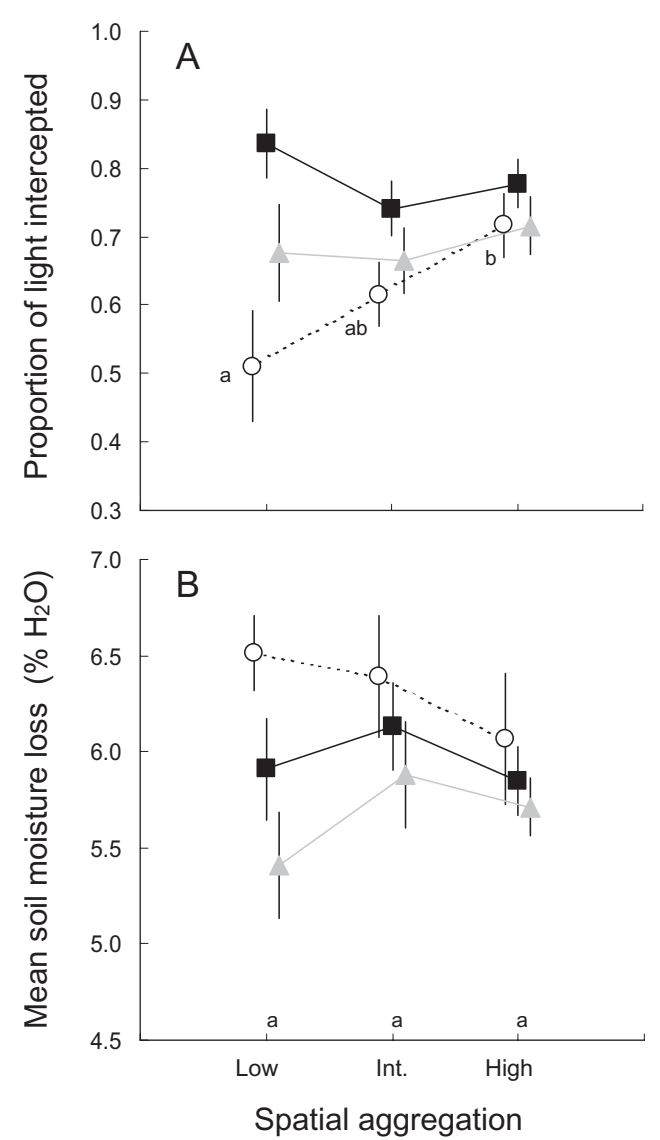

Fig. 5. (A) Proportion of light (PAR) intercepted and (B) mean soil moisture loss over a 12-day drying period, in each spatial aggregation treatment for species mixtures Austrodanthonia and Hypochaeris ( $\bigcirc)$, Hypochaeris and Themeda (ם), and Austrodanthonia and Themeda ( $\triangle$ ). Different letters indicate significant $(P<0.05)$ differences.

0.616), Hypochaeris and Themeda $\left(W_{2}=0.72, P=\right.$ 0.487), or Austrodanthonia and Themeda $\left(W_{2}=0.37\right.$, $P=0.689$ ) (Fig. 4B).

\section{Ecosystem processes}

The proportion of light intercepted by the plant canopy increased significantly as spatial aggregation increased for the mixture of Austrodanthonia and Hypochaeris $\left(W_{2}=3.24, P=0.039\right)$ (Fig. 5A). There were no significant effects of spatial aggregation on light interception for the mixtures of Hypochaeris and Themeda $\left(W_{2}=1.00, P=0.369\right)$, or Austrodanthonia and Themeda $\left(W_{2}=0.34, P=0.711\right)$ (Fig. 5A).

Mean soil moisture loss for the entire soil profile over the 12-day drying period was not significantly affected by spatial aggregation for the mixtures Austrodanthonia and Hypochaeris $\left(W_{2}=2.01, P=0.134\right)$, Hypochaeris and Themeda $\left(W_{2}=0.71, P=0.490\right)$, or Austrodanthonia and Themeda $\left(W_{2}=1.55, P=0.211\right)$ doi:10.1111/j.1442-9993.2007.01813.x
(C) 2008 The Authors

Journal compilation (C) 2008 Ecological Society of Australia 
(Fig. 5B). However, mean soil moisture loss decreased significantly with increasing spatial aggregation in the mixture of Austrodanthonia and Hypochaeris at a number of layers throughout the soil profile, including $10-20 \mathrm{~cm} \quad\left(W_{2}=3.63, P=0.026\right), 30-40 \mathrm{~cm} \quad\left(W_{2}=\right.$ $3.79, P=0.023)$ and $40-50 \mathrm{~cm} \quad\left(W_{2}=3.29, P=\right.$ 0.037 ) (data not shown). For the $0-10 \mathrm{~cm}$ layer in the Hypochaeris and Themeda mixture, soil moisture was significantly lower at intermediate aggregation than low aggregation $\left(W_{2}=3.01, P=0.049\right)$.

\section{DISCUSSION}

\section{Plant biomass}

Spatial aggregation influenced plant biomass attributes for each of the three species examined in this study, however, the nature of these effects depended on the identity of both the target and neighbouring species. The response of plant biomass to different levels of spatial aggregation highlights the importance of spatial aggregation in modulating the relative intensity of intraspecific and interspecific competition.

For Austrodanthonia, plant biomass tended to increase with increasing spatial aggregation, being greatest when in monoculture (Fig. 2A). This result indicates that Austrodanthonia (with its sparse short canopy) is sensitive to interspecific competition, and that as aggregation increases, the level of interspecific competition decreases, allowing greater plant growth. Supporting this notion is theoretical and empirical evidence from previous studies, which suggests that weaker competitors benefit from increased spatial aggregation (Silvertown \& Wilson 2000; Stoll \& Prati 2001).

The relative effects of interspecific and intraspecific competition were also seen to be important in the response of Hypochaeris to aggregation. Hypochaeris produced significantly less plant biomass in monoculture than in either species mixture, indicating high levels of intraspecific competition (Fig. 2B). However, biomass of Hypochaeris tended to be greatest at intermediate aggregation rather than low aggregation. This is possibly because the two negative forces of interspecific and intraspecific competition were greatest in the low-aggregation treatment and the monoculture, respectively, and were balanced at intermediate levels of spatial aggregation. As Hypochaeris has a basal rosette growth form, plant size relative to density is likely to be an important factor in determining this balancing point.

The third species, Themeda, had significantly more plant biomass when in monoculture than in mixture, indicating significant negative effects of interspecific competition (as with Austrodanthonia) (Fig. 2C).
There were no significant changes in root, shoot or total plant biomass for Themeda as the level of spatial aggregation increased from low to high. When competing with Austrodanthonia, Themeda plant biomass did tend to increase with spatial aggregation, although not significantly (Fig. 2C). The pattern was reversed when Themeda was competing with Hypochaeris, with a slight though non-significant decrease in plant biomass as spatial aggregation increased (Fig. 2C).

When the patterns within the high-aggregation patch were examined in detail (Fig. 3), we found that the Themeda plants in the centre of the patch had significantly lower green leaf biomass and non-green shoot biomass than those growing at the edge, regardless of the species it was competing with. Interestingly, this pattern was also evident for Hypochaeris, with shoot (Fig. 3B), root and total plant biomass significantly greater at the edge of the high-aggregation patch than in the centre. Greater biomass at the edge of the high-aggregation patch would be expected for Hypochaeris, owing to the evidence for it experiencing significant intraspecific competition. The occurrence of the same trend for Themeda may be attributable to the reduced competition for light when adjacent to the other two species (of smaller stature), than when adjacent to its conspecifics.

Interestingly, the smaller statured Austrodanthonia had significantly greater shoot biomass at the edge of the high-aggregation patch compared with the centre, when adjacent to the larger statured Themeda (Fig. 3A). Although the edge between Austrodanthonia and Themeda was associated with lower light levels and surface soil moisture availability than the centre of the Austrodanthonia patch, the lower air temperature and greater air humidity at the edge may have generated conditions more amenable to the growth of Austrodanthonia (data not shown).

The observation that plant biomass attributes vary significantly across a monospecific patch has important implications for spatial aggregation in natural communities (Turner 1989; Chesson \& Neuhauser 2002). Large patches are not analogous to monocultures, with the zone of interspecific interaction at the edge of patches displaying markedly different biotic and abiotic characteristics to the centre of patches. Additionally, the potential for some leaves and roots to extend into a neighbouring patch would seem to generate a gradient of interspecific competitive effects across a patch. Models of species interactions and resource competition should therefore recognize both the mean effects of spatial aggregation, as well as finer scale differential effects within a patch.

\section{Complementarity and ecosystem processes}

The key prediction of our study was that spatial aggregation would reduce the complementarity between 
species and hence reduce overall resource use. We postulated that increasing levels of spatial aggregation would reduce complementarity by: (i) reducing the capacity for interspecific interactions through spatial separation; and (ii) reducing the differences in resource acquisition strategies between species through phenotypic plasticity. The first mechanism by which spatial aggregation may reduce complementarity appears inherently true: as species become more separated in space, their capacity for complementary resource use is reduced. To test the second mechanism, we calculated a 'complementarity index' which essentially quantifies the proportional difference between species in the vertical distribution of their green leaf or root biomass. Species would be considered to be more complementary when there is a greater difference in the distribution of their resource-acquiring tissues (in this case, leaves and roots along a vertical axis).

In general, the results of our study do not support the hypothesis that spatial aggregation reduces the complementarity between species and results in less overall resource use. For green leaves, we found that increasing spatial aggregation resulted in a significant decrease in the complementarity index for only one species mixture examined (Austrodanthonia vs. Themeda) (Fig. 4A). As spatial aggregation increased, Austrodanthonia and Themeda became more similar (less complementarity) with respect to their shoot morphologies and light capture strategies. The lack of significant effects of spatial aggregation on complementarity of green leaf distributions for the other two species mixtures may be due to Hypochaeris (with its basal rosettes) having limited capacity to alter the vertical distribution of its leaves. Indeed, the contrast between the basal rosette growth form of Hypochaeris and the tussock growth form of both Austrodanthonia and Themeda is evident throughout the results from this study.

Unexpectedly, the negative effects of spatial aggregation on the complementarity of leaf canopies for the mixture of Austrodanthonia and Themeda did not result in significant effects on light interception (Fig. 5A). In contrast, there was a significant increase in light interception with increasing spatial aggregation for the mixture of Austrodanthonia and Hypochaeris (Fig. 5A), which is counter to our hypothesis that spatial aggregation should reduce resource use. This is most likely due to the increase in shoot biomass of Austrodanthonia as spatial aggregation increases when growing with Hypochaeris (data not shown).

Examination of the distribution of root biomass with depth revealed no significant effects of spatial aggregation on the complementarity between species (Fig. 4B). There was a non-significant trend for the complementarity index to increase with spatial aggregation, for both the Hypochaeris and Themeda mixture, and the Hypochaeris and Austrodanthonia mixture. The generally low values of the root complementarity index (Fig. 4B) indicate very similar patterns in the distribution of root biomass between species, even for mixtures of each grass species (fibrous roots) with Hypochaeris (tap-root). A more detailed analysis of fine root distributions (where resources are absorbed) may have yielded stronger evidence for effects of spatial aggregation on complementarity in root systems (Craine et al. 2002).

In contrast to the root biomass data, soil moisture use showed consistent trends between aggregation treatments and species mixtures (Fig. 5B), although these were only statistically significant for certain layers in the soil profile and for certain species mixtures. If the complementarity in the use of soil moisture decreases with spatial aggregation, we would expect less use of soil moisture as aggregation increases. This general pattern was only observed in one of the mixtures (Austrodanthonia vs. Hypochaeris), and was only significant at certain depth intervals (10$20,30-40$ and $40-50 \mathrm{~cm}$ ). In contrast, soil moisture was depleted significantly more rapidly at intermediate aggregation than low aggregation for the top $10 \mathrm{~cm}$ of soil in the mixture of Hypochaeris and Themeda. Although this result conflicts with the idea of decreasing complementarity in resource use with increasing aggregation, it does align with the observed peak of Hypochaeris biomass at intermediate aggregation (Fig. 2B), as larger plants use more water.

De Boeck et al. (2006) presented a model of the effects of plant spatial aggregation on complementarity in root distributions and subsequent soil resource use, which predicted reduced below-ground resource uptake due to lower complementarity at higher aggregation levels. Our results for the mixture of Austrodanthonia and Hypochaeris (Fig. 5B) tentatively support the predictions of the model presented by De Boeck et al. (2006) with regard to the use of soil moisture. Note however, that De Boeck et al. (2006) only examined the reduction in complementarity due to the reduced zone of interaction between species as they became further separated in space, with the potential for shifting resource acquisition strategies through phenotypic plasticity not included in their model.

In summary, we suggest that spatial aggregation will generally reduce the capacity for complementary resource use owing to species being more separated in space. We found limited evidence in support of our hypothesis that spatial aggregation reduces the differences in the resource acquisition strategies of species through phenotypic plasticity. In many cases, complementarity (through phenotypic plasticity) and resource use were not significantly affected by spatial aggregation, and we observed several trends counter to our hypothesis.

We propose that although spatial aggregation may influence the capacity for complementary resource use 
(as we hypothesized), changes in the number of conspecific versus heterospecific neighbours also influence plant growth (and hence plant size), which will have significant impacts on the capacity for resource use. Clear effects of spatial aggregation on complementarity and resource use are therefore obscured by plant size, which will vary depending upon the identity of neighbouring plants and the competitive pressure they exert (as was seen here when contrasting tussock grasses with a rosette forb). The idiosyncratic response of each species to competition from conspecifics and other species will therefore result in spatial aggregation having no consistent overall effects on complementarity and resource use.

\section{Broader implications}

Here we have shown that under controlled conditions, aggregation in the spatial distribution of species may influence the growth and productivity of species, the degree of complementarity between species and the use of resources by species, although not in a consistent manner. However, the complexity of spatial aggregation as it occurs in natural communities, with overlapping patches of species and diffuse borders between patches (Silvertown \& Wilson 2000), presents serious challenges to gaining a sound empirical understanding of the role of aggregation in influencing interactions between organisms and their use of resources under natural conditions. New approaches, such as the 'virtual experiments' of Turnbull et al. (2007), will be required to improve our understanding of the effects of spatial aggregation.

Regardless of the challenges in understanding the effects of spatial aggregation in natural communities, it is evident that the spatial distribution of the species in a community can be important in determining the consequences of interspecific interactions. The 'mean field assumption' that all species are distributed randomly no longer appears adequate, especially for plant communities (Stoll \& Weiner 2000; Damgaard 2004).

Spatial aggregation may facilitate the coexistence of species and promote increased biodiversity (Rees et al. 1996), but paradoxically it may also reduce the capacity for complementary resource use. How spatial aggregation, biodiversity and complementarity interact to influence ecosystem processes in natural communities is a complex issue that presents significant challenges for empirical investigations. Regardless of the approaches taken, it is evident that both empirical and theoretical studies which examine the effects of biodiversity on ecosystem processes need to pay more attention to how the spatial distributions of species alter this relationship (Schmid et al. 2002; BenedettiCecchi 2005; De Boeck et al. 2006).

\section{ACKNOWLEDGEMENTS}

We thank Sandra Lavorel and Sue McIntyre for advice and comments during the planning and application of this experiment. Ljube Cvetkoski provided valuable assistance in the maintenance of the experiment. We also acknowledge the support funding provided to KM by the Ecological Society of Australia.

\section{REFERENCES}

Benedetti-Cecchi L. (2005) Unanticipated impacts of spatial variance of biodiversity on plant productivity. Ecol. Lett. 8, 791-9.

Bergelson J. (1990) Life after death: site pre-emption by the remains of Poa annua. Ecology 71, 2157-65.

Bourque J. \& Desrochers A. (2006) Spatial aggregation of forest songbird territories and possible implications for area sensitivity. Avian Conserv. Ecol. 1, 3.

Chesson P. \& Neuhauser C. (2002) Intraspecific aggregation and species coexistence: comment. Trends Ecol. Evol. 17, $210-11$.

Craine J., Wedin D., Chapin F. \& Reich P. (2002) Relationship between the structure of root systems and resource use for 11 North American grassland plants. Plant Ecol. 165, 85-100.

Damgaard C. (2004) Inference from plant competition experiments: the effect of spatial covariance. Oikos 107, 225-30.

De Boeck H., Nijs I., Lemmens C. \& Ceulemans R. (2006) Underlying effects of spatial aggregation (clumping) in relationships between plant diversity and resource uptake. Oikos 113, 269-78

Dimitrakopoulos P. \& Schmid B. (2004) Biodiversity effects increase linearly with biotope space. Ecol. Lett. 7, 574-83.

Giller P. (1984) Community Structure and the Niche. Chapman and Hall, London.

Harper J. (1961) Approaches to the study of plant competition. Symp. Soc. Exp. Biol. 15, 1-39.

Hector A. (1998) The effect of diversity on productivity: detecting the role of species complementarity. Oikos 82, 597-9.

Herben T., During H. \& Law R. (2000) Spatio-temporal patterns in grassland communities. In: The Geometry of Ecological Interactions: Simplifying Spatial Complexity (eds U. Diekmann, R. Law \& J. Metz) pp. 48-64. Cambridge University Press, Cambridge.

Hooper D. U., Ewel J., Grime J. et al. (2005) Effects of biodiversity on ecosystem functioning: a consensus of current knowledge. Ecol. Monogr. 75, 3-35.

Law R., Herben T. \& Diekmann U. (1997) Non-manipulative estimates of competition coefficients in a montane grassland community. F. Ecol. 85, 505-17.

Lenssen J., Hershock C., Speek T., During H. \& De Kroon H. (2005) Experimental ramet aggregation in the clonal plant Agrostis stolonifera reduces its competitive ability. Ecology 86, 1358-65.

Maestre F., Escudero A., Martinez I., Guerrero C. \& Rubio A. (2005) Does spatial pattern matter to ecosystem functioning? Insights from biological soil crusts. Funct. Ecol. 19, 566-73.

Monzeglio U. \& Stoll P. (2005) Spatial patterns and species performances in experimental plant communities. Oecologia $145,619-28$ 
Murrell D., Purves D. \& Law R. (2001) Uniting pattern and process in plant ecology. Trends Ecol. Evol. 16, 529-30.

Naeem S., Thompson L., Lawler S., Lawton J. \& Woodfin R. (1994) Declining biodiversity can alter the performance of ecosystems. Nature 368, 734-7.

Perry J. (1995) Spatial analysis by distance index. F. Anim. Ecol. 64, 303-14.

Petchey O. (2003) Integrating methods that investigate how complementarity influences ecosystem functioning. Oikos 101, 323-30.

Rees M., Grubb P. \& Kelly D. (1996) Quantifying the impact of competition and spatial heterogeneity on the structure and dynamics of a four-species guild of winter annuals. Am. Nat. $147,1-32$.

Rejmanek M. (2002) Intraspecific aggregation and species coexistence. Trends Ecol. Evol. 17, 209-10.

Schmid B., Hector A., Huston M., Inchausti P., Nijs I., Leadley P. \& Tilman D. (2002) The design and analysis of biodiversity experiments. In: Biodiversity and Ecosystem Functioning: Synthesis and Perspectives (eds M. Loreau, S. Naeem \& P. Inchausti) pp. 61-75. Oxford University Press, Oxford.

Schmidt W. (1981) Über das Konkurrenzverhalten von Solidago canadensis und Urtica dioica. Verh. Ges. Ökol. 9, 173-88.

Schoener T. (1970) Non-synchronous spatial overlap of lizards in patchy habitats. Ecology 51, 408-18.

Silvertown J. \& Wilson J. (2000) Spatial interactions among grassland plant populations. In: The Geometry of Ecological
Interactions: Simplifying Spatial Complexity (eds U. Diekmann, R. Law \& J. Metz) pp. 28-47. Cambridge University Press, Cambridge.

Simioni G., Gignoux J. \& Le Roux X. (2003) Tree layer spatial structure can affect savanna production and water budget: results of a 3-D model. Ecology 84, 1879-94.

Stoll P. \& Prati D. (2001) Intraspecific aggregation alters competitive interactions in experimental plant communities. Ecology 82, 319-27.

Stoll P. \& Weiner J. (2000) A neighbourhood view of interactions among individual plants. In: The Geometry of Ecological Interactions: Simplifying Spatial Complexity (eds U. Diekmann, R. Law \& J. Metz) pp. 11-27. Cambridge University Press, Cambridge.

Turnbull L., Coomes D., Purves D. \& Rees M. (2007) How spatial structure alters population and community dynamics in a natural plant community. f. Ecol. 79, 79-89.

Turner M. (1989) Landscape Ecology: the effect of pattern on process. Ann. Rev. Ecol. Evol. Syst. 20, 171-97.

Veech J., Crist T. \& Summerville K. (2003) Intraspecific aggregation decreases local species diversity of arthropods. Ecology 84, 3376-83.

Watkinson A., Freckleton R. \& Forrester L. (2000) Population dynamics of Vulpia ciliata: regional, patch and local dynamics. F. Ecol. 88, 1012-29. 